Original

\title{
The clinical and systemic effects of periodontal treatment in diabetic and non-diabetic obese patients
}

\author{
Zekeriya Taşdemir1), Funda Özsarı Taşdemir'1), İsmail Koçyiğit2), Cevat Yazıc13), \\ and Cem A. Gürgan 1$)$ \\ 1)Department of Periodontology, Faculty of Dentistry, Erciyes University, Kayseri, Turkey \\ 2)Deparment of Nephrology, Internal Medicine, Faculty of Medicine, Erciyes University, Kayseri, Turkey \\ 3)Department of Biochemistry, Faculty of Medicine, Erciyes University, Kayseri, Turkey
}

(Received February 25, 2016; Accepted May 21, 2016)

\begin{abstract}
The purpose of the present study was to evaluate the response to periodontal management in obese individuals with poorly controlled diabetes mellitus (DM) and obese individuals without DM. Changes in clinical and biochemical parameters were also investigated. Seventeen obese patients with poorly controlled DM and 14 obese non-DM patients with generalized chronic periodontitis were enrolled. The anthropometric measurements, periodontal parameters, and serum levels of lipid (triglyceride, high-density lipoprotein cholesterol, total cholesterol, low-density lipoprotein cholesterol) and glucose (fasting plasma glucose [FPG], insulin, insulin resistance [IR], hemoglobin [Hb]A1c) metabolism, pro-inflammatory mediators (high-sensitivity C-reactive protein, tumor necrosis factor- $\alpha$ [TNF- $\alpha$ ] and Pentraxim-3), and interleukin-6 were measured before and at 3 months, and 6 months after full-mouth scaling and root planing (FM-SRP) together with fullmouth disinfection (FMD). A significant reduction in TNF- $\alpha(P<0.001)$ values was observed in both groups following periodontal healing. However, significant changes in FPG $(P<0.05)$, HbA1C $(P<0.05)$, and the homeostasis model assessment of IR (HOMA-IR; $P<0.05)$ were only observed after 3 months in the DM group. Our findings suggest that obesity with or
\end{abstract}

Correspondence to Dr. Cem A. Gürgan, Department of Periodontology, Faculty of Dentistry, Erciyes University, Kayseri, Turkey

Fax:+90-3524380657 E-mail: cagurgan@yahoo.com

doi.org/10.2334/josnusd.16-0163

DN/JST.JSTAGE/josnusd/16-0163 without DM does not seem to be a modifying factor for the clinical outcome of FM-SRP and FMD. (J Oral Sci 58, 523-531, 2016)

Keywords: obesity; periodontal therapy; chronic periodontitis; diabetes; cytokines.

\section{Introduction}

Diabetes mellitus (DM) is a known risk factor for hyperinflammation in response to periodontal pathogens (1) and the progression of periodontal disease. DM impairs the connective tissue repair mechanism and decelerates the resolution of inflammation, which causes severe periodontal destruction (2). Increasing evidence suggests that obesity is a direct and indirect risk factor for periodontal disease because it affects glycemic control indirectly and induces the secretion of pro-inflammatory mediators from adipose tissue which affects the influence of dental plaque on the periodontal condition (3).

Periodontitis may negatively influence glycemic control, which can be improved by conventional periodontal management, and lowers the risk of a diabetic co-morbidity, thereby generating a two-way relationship. Moreover, it has been proposed that periodontitis prompts an inflammatory alteration in adipose tissue, which is associated with obesity, DM, and periodontal sickness (4).

Obesity, increased waist circumference (WC), and weight gain may be risk factors for periodontitis (5). However, obesity does not seem to affect the outcome of periodontal treatment (6). The purpose of the present study was to evaluate the clinical response to full-mouth 
Table 1 Demographics, oral hygiene, and anthropometric status of the patients at baseline

\begin{tabular}{|c|c|c|c|}
\hline & Diabetic group & $P$ values & Non-diabetic group \\
\hline $\begin{array}{l}\text { Age (years) }(\text { mean } \pm \text { SD) } \\
\text { (range) }\end{array}$ & $\begin{array}{l}51.3 \pm 8.6 \\
33 \text { to } 63\end{array}$ & NS & $\begin{array}{l}49.2 \pm 9.2 \\
30 \text { to } 62\end{array}$ \\
\hline Female/male $(n)$ & $14 / 3$ & NS & $9 / 5$ \\
\hline $\begin{array}{l}\text { Frequency of brushing teeth }(n) \\
\text { Once a day } \\
\text { Twice a day }\end{array}$ & $\begin{array}{l}16 \\
1\end{array}$ & NS & $\begin{array}{l}12 \\
2\end{array}$ \\
\hline Interdental cleaning (n) & 2 & NS & 1 \\
\hline $\begin{array}{l}\text { Weight }(\mathrm{kg})(\text { mean } \pm \mathrm{SD}) \\
\text { (range) }\end{array}$ & $\begin{array}{l}87.5 \pm 7.0 \\
79 \text { to } 105\end{array}$ & NS & $\begin{array}{l}88.5 \pm 7.0 \\
78 \text { to } 100\end{array}$ \\
\hline $\begin{array}{l}\text { WC }(\mathrm{cm}) \\
\text { Females }(\text { mean } \pm \mathrm{SD}) \\
(\text { range) } \\
\text { Males (mean } \pm \mathrm{SD}) \\
\text { (range) }\end{array}$ & $\begin{array}{l}108.4 \pm 11.3 \\
96 \text { to } 137 \\
113.6 \pm 8.5 \\
104 \text { to } 120\end{array}$ & NS & $\begin{array}{l}106.2 \pm 8.4 \\
95 \text { to } 120 \\
112.4 \pm 7.4 \\
104 \text { to } 120\end{array}$ \\
\hline $\begin{array}{l}\text { BMI }\left(\mathrm{kg} / \mathrm{m}^{2}\right)(\text { mean } \pm \mathrm{SD}) \\
\text { (range) } \\
\left.\text { Class I (BMI of } 30 \text { to } 34.9 \mathrm{~kg} / \mathrm{m}^{2}\right)(n)(\%) \\
\left.\text { Class II (BMI of } 35 \text { to } 39.9 \mathrm{~kg} / \mathrm{m}^{2}\right)(n)(\%) \\
\left.\text { Class III (BMI of } \geq 40 \mathrm{~kg} / \mathrm{m}^{2}\right)(n)(\%)\end{array}$ & $\begin{array}{l}34.1 \pm 1.9 \\
31.6 \text { to } 39.3 \\
11(64.8) \\
6(35.2) \\
-\end{array}$ & $\begin{array}{l}\text { NS } \\
\text { NS }\end{array}$ & $\begin{array}{l}34.1 \pm 3.7 \\
30.8 \text { to } 42.8 \\
10(71.4) \\
3(21.4) \\
1(7.2)\end{array}$ \\
\hline
\end{tabular}

NS: non-significant difference, SD: standard deviation, WC: waist circumference, BMI: body mass index.

scaling and root planing (FM-SRP) in obese patients with poorly controlled DM and without DM. This was done to determine whether periodontal treatment had a systemic effect on the biochemical parameters in obese individuals with poorly controlled DM or without DM.

\section{Case definitions}

\section{Material and Methods}

Chronic periodontitis (CP) was clinically determined based on the following criteria described by Savage et al. (7): presence of $\geq 5$ teeth with $\geq 1$ sites with a probing depth (PD) $\geq 5 \mathrm{~mm}$, clinical attachment loss $(\mathrm{CAL}) \geq 2$ $\mathrm{mm}$, and presence of bleeding upon probing (BOP). Patients with a body mass index (BMI) of $\geq 30 \mathrm{~kg} / \mathrm{m}^{2}$ and a WC of $>88 \mathrm{~cm}$ (females) and $>102 \mathrm{~cm}$ (males) were diagnosed as obese. Obesity was subcategorized as follows: class I, BMI $30-34.9 \mathrm{~kg} / \mathrm{m}^{2}$; class II, $35-39.9 \mathrm{~kg} /$ $\mathrm{m}^{2}$, and class III, $\geq 40 \mathrm{~kg} / \mathrm{m}^{2}$. Type $2 \mathrm{DM}$ was diagnosed according to the diagnostic criteria of the American Diabetes Association (8).

\section{Study groups}

Study participants were categorized into two groups: obese patients without DM and obese patients with DM. Patient characteristics are shown in Table 1. Assessments for eligibility and patient assignment into study groups were done by a clinician (CAG) who was not involved in the clinical proceedings.

Inclusion criteria were as follows: $\mathrm{CP}$, obesity, at least 15 natural teeth, $>25$ years of age, and type $2 \mathrm{DM}$ (in the
DM group). Exclusion criteria were defined as follows: antibiotic or anti-inflammatory drug use within the previous 6 months, pregnancy or lactation, periodontal therapy within the previous 6 months, smoking or history of smoking, alcohol consumption, and use of lipidlowering medications.

Between January 2015 and October 2015, 72 obese patients were enrolled at the Department of Periodontology, Erciyes University, Kayseri, Turkey. Forty-one patients were excluded from the study, (25 did not meet the inclusion criteria and 16 refused to participate). As a result, 31 participants ( 8 males and 23 females; age range, 30-63 years; mean age, $50.4 \pm 8.9$ years) were included in the present study. Two participants in the DM group withdrew participation at 6 months due to loss of contact. Twenty-nine participants completed the study (Fig. 1).

The study details were explained to all participants, and then written informed consent was provided by each patient before initiation of the study protocol. This clinical study was approved by the Erciyes University, Faculty of Medicine Ethics Committee (Decision Number: 2014/606).

\section{Clinical examinations}

The following parameters were evaluated at baseline, 3 months, and 6 months (the end of the study): plaque index (PI) (9); gingival index (GI) (10); PD; percentage of sites with BOP; and clinical attachment loss (CAL). In addition, the percentage and number of deep sites were also calculated. The Decay-Missing-Filling Index (DMFT) 


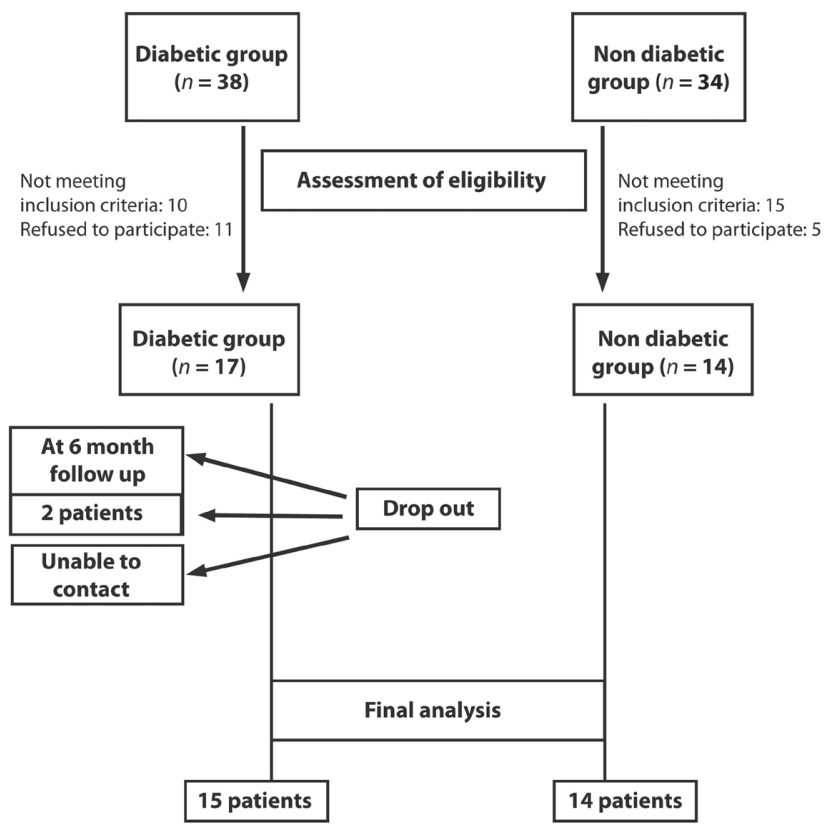

Fig. 1 Flow chart of study procedure.

was recorded. Clinical examinations were repeated 3 and 6 months following periodontal management. All clinical dimensions were obtained from the six sites (mesio-buccal, mid-buccal, disto-buccal, mesio-lingual, mid-lingual, and distolingual) of each tooth using a $15 \mathrm{~mm}$ periodontal probe $(\Psi)$ at baseline and at 3 and 6 months following treatment. All periodontal clinical measurements were made by the same investigator (FOT).

Panoramic and periapical radiographs were obtained to confirm the diagnosis of $\mathrm{CP}$, as well as the diagnosis of various pathological conditions.

To assess the reliability of clinical measurements, ten randomly selected individuals were re-evaluated at baseline and during the treatment period. The reliability of the continuous variables was calculated as the standard deviation of the differences divided by two. The range of the mean error for PD was 0.11-0.16, and this indicated reliable measurements were obtained during the evaluation periods. Cohen's kappa $(\kappa)$ was used to describe the reliability of discrete (GI) and BOP values. Based on duplicate measurements, the $\kappa$ values of GI and BOP were $0.89 \pm 0.04$ and $0.91 \pm 0.05$, respectively.

\section{Serum sampling and biochemical analysis}

At baseline, 3 months, and 6 months after treatment, 20 $\mathrm{mL}$ fasting venous blood samples were collected from the antecubital fossa by an experienced nurse. All blood samples were obtained in the morning between 8:00 and 8:30 am. Blood samples were centrifuged immediately after collection and separated serum samples were stored at $-80^{\circ} \mathrm{C}$ until analysis.

Lipid (triglyceride, high-density lipoprotein cholesterol, total cholesterol, low-density lipoprotein cholesterol), inflammatory factors (interleukin-6 [IL-6], tumor necrosis factor-alpha [TNF- $\alpha]$, high-sensitivity C-reactive protein [hsCRP], pentraxin-3 [PTX3]), and glucose (fasting blood flucose, insulin, hemoglobin [HbAlc]) parameters were measured in the serum samples. Moreover, the homeostasis model assessment of IR (HOMA-IR) was calculated as FBG $\times$ fasting serum insulin level/405. A score $>2.7$ was considered IR.

TNF- $\alpha$ (Invitrogen, Waltham, MA, USA), IL-6 (Invitrogen), and PTX3 (Shanghai Yehua, Shanghai, China) serum levels were measured using a commercial solidphase enzyme-linked immunosorbent assay (ELISA) kit according to the manufacturer's instructions. The plates were read with an Epoch microplate spectrophotometer (BioTec Winooski, VT, USA). The values were expressed as $\mathrm{ng} / \mathrm{mL}$ (PTX3) and $\mathrm{pg} / \mathrm{mL}$ (TNF- $\alpha$ and IL-6); the variation coefficients were: TNF- $\alpha, 4.4 \%$; IL-6, $6.2 \%$; and PTX $3,<10 \%$. All biochemical analyses were performed at Erciyes University in the Department of Biochemistry, Faculty of Medicine.

\section{Periodontal treatment}

All participants received periodontal treatment $2 \mathrm{~h}$ after breakfast following the blood sampling. After local infiltration, FM-SRP was performed by the same investigator (ZT) with manual instruments and ultrasonics. Periodontal therapy was completed within $24 \mathrm{~h}$ during two consecutive visits. The FMD protocol was performed as previously described by Quirynen et al. (11).

At baseline, the participants in both groups were instructed in standard oral hygiene, including plaque control using toothbrushes/interdental brushes and brushing the dorsum of the tongue twice a day. Oral hygiene instructions were repeated at each session. During the periodontal management sessions, obligatory tooth extractions were performed, and referrals for dental treatments were made as soon as periodontal treatment was completed.

\section{Statistical analyses}

The sample size was calculated according to our previous study (12) using data relative to the mean difference and standard deviation (SD) between the HOMA-IR and $\mathrm{HbAlc}$ levels of the obese patients during the experimental period. It was estimated that 11 individuals per group would be sufficient to detect a decrease of 1.3 in HOMA-IR levels (SD, 1.00 ; $\alpha$ error, $0.05 ; \beta$ error, 0.2 ). 
Table 2 Periodontal parameters of the patients

\begin{tabular}{|c|c|c|c|}
\hline & Diabetic group & Between groups & Non-diabetic group \\
\hline \multicolumn{4}{|l|}{ PI } \\
\hline Baseline & $2.2(2.0 \text { to } 2.4)^{\mathrm{a}}$ & NS & $2.4(1.8 \text { to } 2.5)^{\mathrm{a}}$ \\
\hline 3 months & $1.1(0.8 \text { to } 1.4)^{\mathrm{b}}$ & NS & $1.2(0.9 \text { to } 1.4)^{\mathrm{b}}$ \\
\hline 6 months & $0.4(0.4 \text { to } 0.8)^{\mathrm{c}}$ & NS & $0.5(0.4 \text { to } 0.6)^{\mathrm{c}}$ \\
\hline Within the group & $<0.001$ & & $<0.001$ \\
\hline \multicolumn{4}{|l|}{ GI } \\
\hline Baseline & $1.5(1.1 \text { to } 1.7)^{\mathrm{a}}$ & NS & $1.6(1.4 \text { to } 1.8)^{\mathrm{a}}$ \\
\hline 3 months & $0.9(0.7 \text { to } 1.0)^{\mathrm{b}}$ & NS & $0.7(0.7 \text { to } 0.8)^{\mathrm{b}}$ \\
\hline 6 months & $0.4(0.3 \text { to } 0.5)^{\mathrm{c}}$ & NS & $0.4(0.3 \text { to } 0.5)^{\mathrm{c}}$ \\
\hline Within the group & $<0.001$ & & $<0.001$ \\
\hline \multicolumn{4}{|l|}{ PD (mm) } \\
\hline Baseline & $3.1 \pm 0.5(2.6 \text { to } 4.9)^{\mathrm{a}}$ & NS & $2.9 \pm 0.3(2.6 \text { to } 3.8)^{\mathrm{a}}$ \\
\hline 3 months & $2.6 \pm 0.2(2.3 \text { to } 3.0)^{\mathrm{b}}$ & NS & $2.6 \pm 0.2(2.0 \text { to } 2.9)^{\mathrm{b}}$ \\
\hline 6 months & $2.2 \pm 0.2(1.9 \text { to } 2.7)^{\mathrm{c}}$ & NS & $2.2 \pm 0.1(2.0 \text { to } 2.7)^{\mathrm{c}}$ \\
\hline Within the group & $<0.001$ & & $<0.001$ \\
\hline \multicolumn{4}{|l|}{ BOP-positive (\%) } \\
\hline Baseline & $60.0 \pm 15(14 \text { to } 89)^{\mathrm{a}}$ & NS & $62.8 \pm 15(28 \text { to } 84)^{\mathrm{a}}$ \\
\hline 3 months & $38.2 \pm 12(10 \text { to } 47)^{\mathrm{b}}$ & NS & $34.2 \pm 6(19 \text { to } 54)^{b}$ \\
\hline 6 months & $28.3 \pm 10(9 \text { to } 42)^{c}$ & NS & $27.2 \pm 6(13 \text { to } 41)^{c}$ \\
\hline Within the group & $<0.001$ & & $<0.001$ \\
\hline \multicolumn{4}{|l|}{$\mathrm{CAL}(\mathrm{mm})$} \\
\hline Baseline & $3.7 \pm 0.8(2.8 \text { to } 5.4)^{\mathrm{a}}$ & NS & $3.6 \pm 0.5(2.7 \text { to } 4.6)^{\mathrm{a}}$ \\
\hline 3 months & $3.4 \pm 0.7(2.4 \text { to } 5.1)^{\mathrm{b}}$ & NS & $3.3 \pm 0.5(2.5 \text { to } 4.4)^{b}$ \\
\hline 6 months & $3.0 \pm 0.7(2.0 \text { to } 4.6)^{\mathrm{c}}$ & NS & $3.0 \pm 0.4(2.5 \text { to } 4.1)^{\mathrm{c}}$ \\
\hline Within the group & $<0.001$ & & $<0.001$ \\
\hline \multicolumn{4}{|c|}{ Distributions of the PD (\%) } \\
\hline \multicolumn{4}{|c|}{ Baseline } \\
\hline$<3 \mathrm{~mm}$ & 76.1 & NS & 76.4 \\
\hline $4-6 \mathrm{~mm}$ & 22.6 & NS & 22.8 \\
\hline$>6 \mathrm{~mm}$ & 1.3 & NS & 0.8 \\
\hline \multicolumn{4}{|l|}{3 months } \\
\hline$<3 \mathrm{~mm}$ & 85.7 & NS & 91.1 \\
\hline $4-6 \mathrm{~mm}$ & 13.6 & NS & 8.6 \\
\hline$>6 \mathrm{~mm}$ & 0.7 & NS & 0.3 \\
\hline \multicolumn{4}{|l|}{6 months } \\
\hline$<3 \mathrm{~mm}$ & 96.3 & NS & 98.6 \\
\hline $4-6 \mathrm{~mm}$ & 3.7 & NS & 1.4 \\
\hline$>6 \mathrm{~mm}$ & 0 & & 0 \\
\hline \multicolumn{4}{|l|}{ Number of teeth $(n)$} \\
\hline Baseline & $25.8 \pm 2.6(18$ to 28$)$ & NS & $25.9 \pm 1.8(22$ to 28$)$ \\
\hline 3 months & $24.8 \pm 2.3(18$ to 28$)$ & NS & $25.3 \pm 1.9(22$ to 28$)$ \\
\hline 6 months & $24.1 \pm 2.5(18$ to 28$)$ & NS & $24.2 \pm 2.4(20$ to 28$)$ \\
\hline Within the group & NS & & NS \\
\hline \multicolumn{4}{|c|}{ Number of decayed teeth $(n)$} \\
\hline Baseline & $3.8 \pm 2.5(0 \text { to } 10)^{\mathrm{a}}$ & NS & $3.7 \pm 1.8(0 \text { to } 8)^{\mathrm{a}}$ \\
\hline 3 months & $2.3 \pm 2.3(0 \text { to } 8)^{b}$ & NS & $2.6 \pm 1.9(0 \text { to } 6)^{\mathrm{b}}$ \\
\hline 6 months & $1.2 \pm 2.6(0 \text { to } 5)^{\mathrm{c}}$ & NS & $1.4 \pm 1.8(0 \text { to } 5)^{\mathrm{c}}$ \\
\hline Within the group & $<0.001$ & & $<0.001$ \\
\hline \multicolumn{4}{|l|}{ DMFT index } \\
\hline Baseline & $10.7 \pm 5.0(3$ to 18$)$ & NS & $10.5 \pm 5.7(1$ to 22$)$ \\
\hline 3 months & $10.8 \pm 5.1(3$ to 18$)$ & NS & $10.6 \pm 5.7(1$ to 22$)$ \\
\hline 6 months & $11.2 \pm 5.3(3$ to 18$)$ & NS & $10.5 \pm 5.7(1$ to 22$)$ \\
\hline Within the group & NS & & NS \\
\hline
\end{tabular}

In addition, the estimated minimum number for detecting a decrease of 2.1 in the HbA1c levels (SD, 1.4; $\alpha$ error, 0.05 ; $\beta$ error, 0.2 ) was ten patients per group.

Normality of the data was tested using the KolmogorovSmirnov test. The Student's $t$-test was used to analyze the baseline parametric data, including age, weight, WC, and
BMI. Comparisons were made using the Chi-square test and the exact method analysis for categorical variable samples.

The repeated measures two-way analysis of variance (ANOVA) test was utilized for both groups to analyze the repeated measurements. In addition, results were 
Table 3 Lipid and glucose levels in patient subjects

\begin{tabular}{|c|c|c|c|}
\hline & Diabetic group & Between groups & Non-diabetic group \\
\hline \multicolumn{4}{|l|}{ HDL } \\
\hline Baseline & $50.1 \pm 14.2(33.1$ to 77.7$)$ & NS & $49.4 \pm 15.6(25.0$ to 78.6$)$ \\
\hline 3 months & $52.3 \pm 13.3(25.4$ to 74.0$)$ & NS & $46.5 \pm 12.2(27.0$ to 70.3$)$ \\
\hline 6 months & $48.0 \pm 10.8(29.0$ to 67.0$)$ & NS & $45.4 \pm 14.1(22.0$ to 71.5$)$ \\
\hline Within the group & 0.068 & & 0.059 \\
\hline \multicolumn{4}{|l|}{ LDL } \\
\hline Baseline & $138.3 \pm 39.1(31.6$ to 190.5$)$ & 0.017 & $102.6 \pm 27.4(60.5$ to 147.4$)$ \\
\hline 3 months & $142.6 \pm 45.8$ ( 36.8 to 213.6$)$ & NS & $117.4 \pm 34.4(69.2$ to 190.2$)$ \\
\hline 6 months & $135.0 \pm 38.0(41.0$ to 199.9$)$ & NS & $111.4 \pm 36.5$ (48.5 to 179.6$)$ \\
\hline Within the group & 0.824 & & 0.074 \\
\hline \multicolumn{4}{|l|}{$\mathrm{TC}$} \\
\hline Baseline & $221.5 \pm 46.0(125$ to 305$)$ & NS & $192.5 \pm 31.4(134$ to 243$)$ \\
\hline 3 months & $230.9 \pm 52.7(121$ to 300$)$ & NS & $200.2 \pm 35.2(147$ to 275$)$ \\
\hline 6 months & $215.8 \pm 40.6(136$ to 280$)$ & NS & $192.7 \pm 37.6(127$ to 260$)$ \\
\hline Within the group & 0.148 & & 0.412 \\
\hline \multicolumn{4}{|l|}{ TRG } \\
\hline Baseline & 167.8 (127.7 to 200.0$)$ & NS & 166.4 (116.5 to 212.0$)$ \\
\hline 3 months & 178.5 (117.0 to 228.6$)$ & NS & $157.9(120.0$ to 220.1$)$ \\
\hline 6 months & $169.0(104.0$ to 215.0$)$ & NS & 167.5 (73.0 to 213.6$)$ \\
\hline Within the group & 0.762 & & 0.136 \\
\hline \multicolumn{4}{|l|}{ HgAlc } \\
\hline Baseline & $7.4(6.9 \text { to } 8.4)^{\mathrm{a}}$ & $<0.001$ & $5.3(5.2$ to 5.6$)$ \\
\hline 3 months & $7.3(5.8 \text { to } 8.3)^{\mathrm{b}}$ & $<0.001$ & $5.2(5.1$ to 5.4$)$ \\
\hline 6 months & $7.4(5.7 \text { to } 8.6)^{\mathrm{a}, \mathrm{b}}$ & $<0.001$ & $5.2(5.1$ to 5.5$)$ \\
\hline Within the group & 0.020 & & 0.639 \\
\hline \multicolumn{4}{|l|}{ Insulin } \\
\hline Baseline & $14.5(10.6$ to 22.0$)$ & NS & 18.3 (10.7 to 22.6$)$ \\
\hline 3 months & $14.0(7.8$ to 18.5$)$ & NS & $14.7(7.8$ to 18.6$)$ \\
\hline 6 months & $14.0(6.8$ to 18.1$)$ & NS & $17.1(8.5$ to 23.4$)$ \\
\hline Within the group & NS & & NS \\
\hline \multicolumn{4}{|l|}{ Glucose } \\
\hline Baseline & $142.0(128.0 \text { to } 162.0)^{\mathrm{a}, \mathrm{b}}$ & $<0.001$ & 86.5 (80.5 to 92.2$)$ \\
\hline 3 months & $138.0(116.0 \text { to } 185.0)^{\mathrm{a}}$ & $<0.001$ & $91.5(78.5$ to 96.5$)$ \\
\hline 6 months & $153.0(121.0 \text { to } 218.0)^{\mathrm{b}}$ & $<0.001$ & $90.5(78.5$ to 97.5$)$ \\
\hline Within the group & 0.023 & & 0.845 \\
\hline \multicolumn{4}{|l|}{ HOMA-IR } \\
\hline Baseline & 5.35 (4.21 to 8.8$)$ & $<0.001$ & $3.93(2.25$ to 5.06$)$ \\
\hline 3 months & $4.5(2.31$ to 8.22$)$ & 0.001 & $3.0(1.8$ to 4.18$)$ \\
\hline 6 months & $5.4(2.20$ to 6.57$)$ & 0.003 & $3.87(2.05$ to 5.37$)$ \\
\hline Within the group & NS & & NS \\
\hline
\end{tabular}

adjusted for age and sex to obtain the corrected $P$ values. Moreover, we performed log transformation of variables that were not normally distributed. Bonferroni correction was used for post hoc comparisons. Missing values were attributed using the last observation carried forward method. A commercial statistical software (SPSS Statistics V21, IBM, Chicago, IL, USA) was used for analyses with the significance level set at $P=0.05$.

\section{Results}

There were no significant differences in the demographic characteristics, oral hygiene habits, and anthropometric status between the groups. During the evaluation period, none of the participants reported changes in their lifestyle or eating habits, and no alterations were observed in the anthropometric measurements for both groups (Table 1).
No patients took anti-inflammatory and/or antimicrobial medication during the evaluation period.

Periodontal parameters were similar at baseline for both groups. None of the patients had any complaints following periodontal treatment. There were no significant differences between groups in the follow-up period. However, intra-group analysis revealed significant improvements at the 6-month follow-up. The numbers of decayed teeth were similar for both groups at all evaluations, these were significantly reduced in both groups after restorative dental treatments following periodontal therapy (Table 2). In addition, patients in both groups were in good health when they completed the study. No adverse effects were reported for periodontal treatment.

No significant differences were observed in the lipid profiles and insulin levels between the study groups 
Table 4 Values of inflammatory parameters in patient subjects

\begin{tabular}{|c|c|c|c|}
\hline & Diabetic group & Between groups & Non-diabetic group \\
\hline \multicolumn{4}{|l|}{ TNF- $\alpha$} \\
\hline Baseline & $14.6(12.0 \text { to } 17.3)^{\mathrm{a}}$ & NS & $12.8(10.5 \text { to } 15.0)^{\mathrm{a}}$ \\
\hline 3 months & $10.9(6.3 \text { to } 12.4)^{\mathrm{a}}$ & NS & $11.3(7.2 \text { to } 16.1)^{\mathrm{a}}$ \\
\hline 6 months & $5.1(4.1 \text { to } 6.4)^{\mathrm{b}}$ & NS & $3.8(2.6 \text { to } 6.4)^{\mathrm{b}}$ \\
\hline Within the group & $<0.001$ & & $<0.001$ \\
\hline \multicolumn{4}{|l|}{ IL-6 } \\
\hline Baseline & $2.32(1.72$ to 4.7$)$ & NS & $2.23(1.8$ to 4.6$)$ \\
\hline 3 months & $2.04(1.8$ to 2.4$)$ & NS & $2.13(1.8$ to 3.0$)$ \\
\hline 6 months & $2.00(1.8$ to 2.4$)$ & NS & 2.04 (1.8 to 2.4$)$ \\
\hline Within the group & NS & & NS \\
\hline \multicolumn{4}{|l|}{ PTX-3 } \\
\hline Baseline & $4.38(3.7$ to 6.1$)$ & NS & $4.76(3.1$ to 7.9$)$ \\
\hline 3 months & $4.31(3.0$ to 5.1$)$ & NS & $4.50(3.0$ to 6.9$)$ \\
\hline 6 months & 4.43 (3.7 to 5.6$)$ & NS & $4.62(3.0$ to 6.8$)$ \\
\hline Within the group & NS & & NS \\
\hline \multicolumn{4}{|l|}{ HsCrp } \\
\hline Baseline & $3.6(3.4$ to 10.2$)$ & NS & $3.4(3.4$ to 5.4$)$ \\
\hline 3 months & $3.4(3.4$ to 10.7$)$ & NS & $3.3(3.2$ to 5.4$)$ \\
\hline 6 months & $3.6(3.2$ to 8.2$)$ & NS & $3.3(3.2$ to 8.2$)$ \\
\hline Within the group & NS & & NS \\
\hline
\end{tabular}

(Table 3). However, HbA1c levels were significantly higher in the DM group $(P<0.001)$ than the non-DM group in all examinations. In addition, HbAlc levels were significantly reduced at the 3-month follow-up in the DM group $(P=0.02)$. HOMA-IR was reduced at the 3-month follow-up in both groups $(P=0.042)$, but HOMA-IR levels were significantly $(P<0.01)$ higher in the DM group than the non-DM group (Table 3 ).

No differences were observed in inflammatory parameters using inter-group or intra-group analyses, except for TNF- $\alpha$ levels. TNF- $\alpha$ levels were significantly reduced at the 6 month follow-up visit in both groups $(P<0.001)$ (Table 4).

\section{Discussion}

We made several important observations during our study. Firstly, DM did not affect the clinical response to periodontal treatment. Secondly, only levels of TNF- $\alpha$ and $\mathrm{HbAlc}$ were significantly altered in the diabetic group, and no changes in lipid parameters were observed in both groups.

$\mathrm{SRP}$ is an effective method for treating $\mathrm{CP}$. The addition of FMD to FM-SRP or quadrant SRP (Q-SRP) is effective $(13,14)$ and does not cause any obvious discomfort or change in one's quality of life (15). Moreover, based on a recent meta-analysis, FMD, FMS, and Q-SRP all effectively manage CP. Comparison of FMD and Q-SRP revealed that FMD was moderately better than Q-SRP in reducing probing depth and increasing clinical attachment level (13). Therefore, we used FMD and FM-SRP as the treatment of choice to restrict the cumulative effect of bacteremia and avoid repeated acute inflammation during treatment $(16,17)$. As a result, significant improvements were observed in all periodontal parameters throughout the study period in both groups.

It can be argued that only poorly controlled DM patients can be compared with systemically healthy non-obese patients as the control group. However, evidence suggests that obesity is the main factor for controlling DM $(18,19)$. The prevalence of obesity has not been associated with DM in the Turkish population, but Daousi et al. (18) reported that $86 \%$ of DM patients were overweight or obese. We designed the present study based on these findings.

Recent studies evaluating the effect of periodontal treatment on inflammatory mediators in obese patients (BMI $\geq 30 \mathrm{~kg} / \mathrm{m}^{2}$ ) reported a significant reduction in circulating pro-inflammatory cytokines (20-22). Gonçalves et al. (23) reported less of a decrease in TNF- $\alpha$ levels in obese patients compared with non-obese patients following non-surgical periodontal treatment. We have previously demonstrated (12) a significant decrease in TNF- $\alpha$ levels in non-DM obese patients and IL-6 levels in obese non-DM and healthy individuals. However, in this study, only TNF- $\alpha$ levels were significantly reduced after 3 months.

Although previous results are inconsistent with ours $(12,23,24)$, IL-6 and hsCRP levels are generally reduced in diabetic and obese patients following periodontal treatment. Other inflammatory mediators (IL-6, hsCRP, and PTX-3) were not significantly different in the intergroup or intra-group analysis in our study. This could be 
explained by the inclusion of patients with moderately severe periodontal problems and mostly class I obesity (BMI of $30-34.9 \mathrm{~kg} / \mathrm{m}^{2}$ ). The magnitude of systemic inflammation in these individuals could be lower compared with more severely obese patients (25).

PTX-3 is an early marker of innate immunity and inflammatory responses in diabetic patients. It is structurally linked to short pentraxins, including hsCRP, and is strongly expressed in atherosclerotic lesions and in patients with chronic kidney disease (26). PTX-3 is synthesized by several cells and tissues, including macrophages, fat tissue, and vascular endothelial cells, unlike hsCRP, which is only produced by hepatocytes (27).

Various cross-sectional studies have been published (28-30), however only one study (31) has investigated alterations in PTX-3 levels after 1 month of periodontal treatment. This makes it difficult to interpret our results in relation to the findings of previous studies. Mathew et al. (31) reported a significant decrease in PTX-3 levels after 1 month of periodontal therapy. However, we did not find any significant changes in PTX-3 levels throughout this study. Clinically, this is a very early stage to evaluate altered PTX-3 levels. In addition, PTX-3 and $\mathrm{HsCrp}$ belong to the same family; therefore, it is not unexpected that PTX-3 levels did not change (32). This result may also be explained by the inclusion of patients with moderate periodontitis.

Periodontal treatment reduced HbAlc levels 3-4 months after treatment $(33,34)$. These reports support our findings that FM-SRP with FMD reduced $\mathrm{HbAlc}$ levels in diabetic patients after 3 months. However, the effect we observed at 3 months was no longer significant after 6 months, which is also in agreement with results reported in another study (35).

The effect of periodontal disease on DM may be caused by a systemic increase in pro-inflammatory mediators that exacerbate IR $(1,12)$. Successful periodontal management appears to have positive effects on the metabolic control of type 2 DM $(1,36,37)$. Type $2 \mathrm{DM}$ is a multiple-risk-factor syndrome, but decreased insulin sensitivity, or IR, is essential to the development of this metabolic disease (36). The pro-inflammatory cytokine TNF- $\alpha$ is produced by adipose tissues in obese individuals and is a predominant player in inducing IR $(38,39)$ Therefore, the improvement in metabolic control of DM via enhanced insulin sensitivity due to a decrease in peripheral TNF- $\alpha$ concentration can be achieved by periodontal treatment.

HOMA-IR levels were significantly different between the groups at all follow-up examinations. Only the diabetic group showed a significant reduction in intra- group analysis for HOMA-IR value in our study. We compared the obese group in the present study with an obese group from a previous study, where periodontal therapy reduced HOMA-IR by approximately $26 \%$ after 3 months (12). Although we observed a reduction in HOMA-IR after 3 months, the reduction ratio was lower. However, the baseline values in the previous study were higher than in the present study (4.9 vs. 3.9) and the reduction of HOMA-IR by periodontal therapy was higher than our 3-month value (3.6 vs. 3.0). The HOMA-IR levels reported here were better than the previous study at baseline and after 3 months (12). Similar to our findings, Sun et al. (40) reported that periodontal therapy reduced HOMA-IR levels in diabetic patients. However, different methodologies were used and we should compare these findings with caution. Sun et al. (39) evaluated only diabetic patients and obesity was an exclusion factor.

Only TNF- $\alpha$ values were significantly reduced in both groups. Therefore, we partially concluded that periodontal treatment has no systemic effect on the tested parameters. However, the alterations in FPG $(P<0.05), \operatorname{HbA1C}(P$ $<0.05)$, and HOMA-IR $(P<0.05$ after 3 months) were only observed in the DM group.

There were some limitations in the present study. First, although we calculated that 12 patients per group was sufficient to obtain significant results, the high variability among the individuals may have resulted in the observed discrepancies. Second, the inflammatory parameters were evaluated only in serum samples and not in gingival crevicular fluid. Third, our study population consisted mostly of class I obese patients, so obesity subgroups could not be compared. Fourth, we did not analyze any patients with severe periodontitis.

Within the limits of this prospective study, we concluded that the clinical periodontal response to FM-SRP and FMD was successful and that TNF- $\alpha$ levels were significantly reduced. In addition, $\mathrm{HbAlC}$ and HOMA-IR were altered in obese DM patients at the 3 -month evaluation.

\section{Acknowledgments}

This study was supported by a grant from the Scientific Research Projects of Erciyes University (Grant number: TDH 2015-5657).

\section{Conflict of interest}

The authors declare that there is no conflict of interest concerning the contents of the study.

\section{References}

1. Mealey BL, Oates TW (2006) Diabetes mellitus and periodontal diseases. J Periodontol 77, 1289-1303. 
2. Beikler T, Kuczek A, Petersilka G, Flemming TF (2002) In-dental-office screening for diabetes mellitus using gingival crevicular blood. J Clin Periodontol 29, 216-218.

3. Saito T, Shimazaki Y (2007) Metabolic disorders related to obesity and periodontal disease. Periodontol 2000 43, 254-266.

4. Levine RS (2013) Obesity, diabetes and periodontitis--a triangular relationship? Br Dent J 215, 35-39.

5. Keller A, Rohde JF, Raymond K, Heitmann BL (2015) Association between periodontal disease and overweight and obesity: a systematic review. J Periodontol 86, 766-776.

6. Nascimento GG, Leite FR, Correa MB, Peres MA, Demarco FF (2016) Does periodontal treatment have an effect on clinical and immunological parameters of periodontal disease in obese subjects? A systematic review and meta-analysis. Clin Oral Investig 20, 639-647.

7. Savage A, Eaton KA, Moles DR, Needleman I (2009) A systematic review of definitions of periodontitis and methods that have been used to identify this disease. J Clin Periodontol 36, 458-467.

8. American Diabetes Association (2004) Diagnosis and classification of diabetes mellitus. Diabetes Care 27, S5-10.

9. Silness J, Löe H (1966) Periodontal disease in pregnancy. 3. Response to local treatment. Acta Odontol Scand 24, 747-759.

10. Loe H, Silness J (1963) Periodontal disease in pregnancy. 1. Prevealence and severeity. Acta Odontol Scand 21, 533-551.

11. Quirynen M, Bollen CM, Vandekerckhove BN, Dekeyser C, Papaioannou W, Eyssen H (1995) Full- vs. partial-mouth disinfection in the treatment of periodontal infections: shortterm clinical and microbiological observations. J Dent Res 74, 1459-1467.

12. Altay U, Gürgan CA, Ağbaht K (2013) Changes in inflammatory and metabolic parameters after periodontal treatment in patients with and without obesity. J Periodontol 84, 13-23.

13. Fang H, Han M, Li QL, Cao CY, Xia R, Zhang ZH (2015) Comparison of full-mouth disinfection and quadrant-wise scaling in the treatment of adult chronic periodontitis: a systematic review and meta-analysis. J Periodontal Res 51, 417-430.

14. Eberhard J, Jepsen S, Jervøe-Storm PM, Needleman I, Worthington HV (2015) Full-mouth treatment modalities (within 24 hours) for chronic periodontitis in adults. Cochrane Database Syst Rev 17, 4:CD004622. doi: 10.1002/14651858. CD004622.pub3.

15. Santuchi CC, Cortelli JR, Cortelli SC, Cota LO, Fonseca DC, Alencar CO et al. (2016) Scaling and root planing per quadrant versus one-stage full-mouth disinfection: assessment of the impact of chronic periodontitis treatment on quality of life-a clinical randomized controlled trial. J Periodontol 87, 114-123.

16. Preus HR, Dahlen G, Gjermo P, Baelum V (2015) Microbiologic observations after four treatment strategies among patients with periodontitis maintaining a high standard of oral hygiene: secondary analysis of a randomized controlled clinical trial. J Periodontol 86, 856-865.

17. Graziani F, Cei S, Orlandi M, Gennai S, Gabriele M, Filice $\mathrm{N}$ et al. (2015) Acute-phase response following full-mouth versus quadrant non-surgical periodontal treatment: a randomized clinical trial. J Clin Periodontol 42, 843-852.

18. Daousi C, Casson IF, Gill GV, MacFarlane IA, Wilding JP, Pinkney JH (2006) Prevalence of obesity in type 2 diabetes in secondary care: association with cardiovascular risk factors. Postgrad Med J 82, 280-284.

19. Field AE, Coakley EH, Must A, Spadano JL, Laird N, Dietz WH et al. (2001) Impact of overweight on the risk of developing common chronic diseases during a 10-year period. Arch Intern Med 161, 1581-1586.

20. Acharya A, Bhavsar N, Jadav B, Parikh H (2010) Cardioprotective effect of periodontal therapy in metabolic syndrome: a pilot study in Indian subjects. Metab Syndr Relat Disord 8, 335-341.

21. Correa FOB, Gonçalves D, Figueredo CMS, Bastos AS, Gustafsson A, Orrico SRP (2010) Effect of periodontal treatment on metabolic control, systemic inflammation and cytokines in patients with type 2 diabetes. J Clin Periodontol 37, 53-58.

22. Zuza EP, Barroso EM, Carrareto AL, Pires JR, Carlos IZ, Theodoro LH et al. (2011) The role of obesity as a modifying factor in patients undergoing non-surgical periodontal therapy. J Periodontol 82, 676-682.

23. Gonçalves TE, Zimmermann GS, Figueiredo LC, Souza Mde C, da Cruz DF, Bastos MF et al. (2015) Local and serum levels of adipokines in patients with obesity after periodontal therapy: one-year follow-up. J Clin Periodontol 42, 431-439.

24. Correa FO, Gonçalves TE, Figueredo CM, Bastos AS, Gustafsson A, Orrico SR (2010) Effect of periodontal treatment on metabolic control, systemic inflammation and cytokines in patients with type 2 diabetes. J Clin Periodontol 37, 53-58.

25. Keller A, Rohde JF, Raymond K, Heitmann BL (2015) Association between periodontal disease and overweight and obesity: a systematic review. J Periodontol 86, 766-776.

26. Tong M, Carrero JJ, Qureshi AR, Anderstam B, Heimbürger O, Bárány P et al. (2007) Plasma pentraxin 3 in patients with chronic kidney disease: associations with renal function, protein-energy wasting, cardiovascular disease, and mortality. Clin J Am Soc Nephrol 2, 889-897.

27. Suliman ME, Yilmaz MI, Carrero JJ, Qureshi AR, Saglam M, Ipcioglu OM et al. (2008) Novel links between the long pentraxin 3, endothelial dysfunction, and albuminuria in early and advanced chronic kidney disease. Clin J Am Soc Nephrol 3, 976-985.

28. Pradeep AR, Kathariya R, Raghavendra NM, Sharma A (2011) Levels of pentraxin-3 in gingival crevicular fluid and plasma in periodontal health and disease. J Periodontol 82, 734-741.

29. Fujita Y, Ito H, Sekino S, Numabe Y (2012) Correlations between pentraxin 3 or cytokine levels in gingival crevicular fluid and clinical parameters of chronic periodontitis. Odon- 
tology 100, 215-221.

30. Gümüş P, Nizam N, Nalbantsoy A, Özçaka Ö, Buduneli $N$ (2014) Saliva and serum levels of pentraxin-3 and interleukin- $1 \beta$ in generalized aggressive or chronic periodontitis. J Periodontol 85, e40-46.

31. Mathew V, Varghese S, Sankari M, Jayakumar ND (2015) Evaluation of pentraxin 3 in chronic periodontitis patients before and after the treatment. Int J Med Exercise Sci 1, 9-15.

32. Deban L, Jaillon S, Garlanda C, Bottazzi B, Mantovani A (2010) Pentraxins in innate immunity: lessons from PTX3. Cell Tissue Res 343, 237-249.

33. Chapple IL,Genco R (2013) Diabetes and periodontal diseases: consensus report of the Joint EFP/AAP Workshop on Periodontitis and Systemic Diseases. J Periodontol 84, Suppl 4, S106-112.

34. Botero JE, Rodríguez C, Agudelo-Suarez AA (2016) Periodontal treatment and glycemic control in patients with diabetes and periodontitis: an umbrella review. Aust Dent J 61, 134-148.

35. Vergnes JN (2015) Review finds periodontal treatment has short term benefits for diabetics. Evid Based Dent 16, 78-90.

36. Nishimura F, Murayama Y (2001) Periodontal inflammation and insulin resistance--lessons from obesity. J Dent Res 80, 1690-1694.

37. Casanova L, Hughes FJ, Preshaw PM (2014) Diabetes and periodontal disease : a two-way relationship. Br Dent J 217, 433-437.

38. Guilherme A, Virbasius JV, Puri V, Czech MP (2008) Adipocyte dysfunctions linking obesity to insulin resistance and type 2 diabetes. Nat Rev Mol Cell Biol 9, 367-377.

39. Jung UJ, Choi MS (2014) Obesity and its metabolic complications: the role of adipokines and the relationship between obesity, inflammation, insulin resistance, dyslipidemia and nonalcoholic fatty liver disease. Int J Mol Sci 15, 6184-6223.

40. Sun WL, Chen LL, Zhan SZ, Wu YM, Ren YZ, Qin GM (2011) Inflammatory cytokines, adiponectin, insulin resistance and metabolic control after periodontal intervention in patients with type 2 diabetes and chronic periodontitis. Intern Med 50, 1569-1574. 